\title{
LAS UNIVERSIDADES: FORMADORAS DE LOS ARTÍFICES DE LA PAZ
}

Roberto Valdés Valle

Escuela Superior de Economía y Negocios, ESEN

robertovaldes@hotmail.com

Se cumplieron 25 años de la firma de los Acuerdos de Paz en El Salvador (1992-2017) y nuestro país sigue siendo uno de los más violentos del mundo. Ciertamente, si nos comparamos con los tiempos del conflicto, la violencia que vivimos en la actualidad resulta mucho más insensata e irracional, que destruye vidas y proyectos económicos y de desarrollo por lógicas incomprensibles e injustificables desde todo punto de vista.

Hasta ahora, todo intento de superar esta lamentable situación parece haber fallado. Políticos, fuerzas policiales y militares vienen ensayando varios intentos de solución, y las universidades se han dedicado sobre todo a analizar el problema, determinar sus causas y proponer soluciones. En otras palabras, las universidades han enfocado el fenómeno solo desde una de sus funciones sustantivas, la investigación. Sin embargo, muy raramente las universidades del país se han planteado cómo contribuir a la solución de esta situación de violencias desde la docencia.

Las aulas universitarias -independientemente de la carrera o especialidad que se enseñe- deben fomentar entre los estudiantes una cultura de diálogo, de democracia inclusiva, que nos ayude a superar la intolerancia y fomente el respeto a la diferencia. Ese podría ser el aporte que, desde la función de la docencia, las instituciones de Educación Superior de El Salvador podrían hacer a la construcción de la paz en el país. ¿Cómo hacerlo de manera concreta y efectiva? Acá la pregunta se enfoca en determinar qué tipo de actitudes o virtudes son las que los profesores deben fomentar en las aulas universitarias. En otras palabras, cuál debería ser el perfil de los estudiantes que se gradúan de nuestras universidades y qué competencias o capacidades específicas se deben fomentar en ellos para que se constituyan en auténticos constructores de la paz.

En 1986, Ignacio Ellacuría, en su calidad de rector de la Universidad Centroamericana José Simeón Cañas, ofreció un discurso de graduación que tituló precisamente «Artífices de la paz en El Salvador». Se trata de un texto poco estudiado, pero que resulta muy adecuado para nuestro contexto por cuanto trató de esclarecer cuál debía ser el compromiso de los graduados universitarios con la construcción de la paz de El Salvador en el contexto del conflicto armando que se vivía en aquel momento. En ese entonces, Ellacuría se preguntaba de qué manera podrían los graduados universitarios contribuir a la construcción de la paz en el país. A su juicio, no se trataba de dar una respuesta desde el punto de vista político, sino desde una perspectiva ética y cristiana.

Al releer esas páginas más de treinta años después, me parece que Ellacuría imponía graves responsabilidades sobre los hombros de los graduados. ¿Se trataba de un típico discurso utópico? Quizá sí, si lo vemos desde el punto de vista de los graduados. Es utópico esperar que se convier- 
tan en constructores de la paz si no los hemos preparado para ello. Por el contrario, no es utópico si este discurso se concibe como una guía para las universidades, es decir, como una especie de orientación que ayude a perfilar los objetivos específicos que deberían enfatizar las universidades a la hora de educar en valores para la paz a sus estudiantes.

Para Ellacuría, los graduados serían verdaderos artífices de la paz si enfocaran sus actividades profesionales desde las virtudes de la justicia, la misericordia y la prudencia. Se trata de virtudes, porque para dominarlas debidamente deben ser practicadas una y otra vez, como se debe practicar una y otra vez si uno desea aprender a tocar un instrumento musical. Por lo tanto, nada mejor que las universidades para asumir el reto de propiciar entre sus estudiantes la práctica constante de estas tres virtudes.

En primer lugar, hay que enseñar la práctica de la justicia, porque «la paz es obra de la justicia» (Is. 32:37). Debemos estimular en los estudiantes la aspiración de trabajar como profesionales capaces de producir los «bienes y servicios indispensables para que todos tengan lo que les es debido», pero también «haciendo conciencia de la injusticia y despertando conciencias para que en todo reine la justicia». Así, los estudiantes de nuestras universidades deberían distinguirse por tratar de «superar la injusticia e instaurar un nuevo orden de relaciones sociales mucho más justo y equitativo del que hoy se da entre nosotros».

En segundo lugar, debe fomentarse en los estudiantes la virtud de la misericordia, para evitar la grave tentación de luchar por la justicia por «odio y revanchismo». Para Ellacuría, «la actitud y el hábito de la misericordia son indispensables para encontrar la verdadera paz», porque la misericordia es una forma de amor, «pero de un amor preferencial por quienes son víctimas de la injusticia, que lejos de convertirse en odio de quienes las causan se transforma en llamada a la conversión».

Finalmente, las universidades deberían esforzarse en fomentar la práctica de la prudencia, quizá la virtud por excelencia de la moral clásica. Pero, aclara Ellacuría, la prudencia no debe entenderse como «el refugio de indecisos y cobardes». Quizá podríamos pensar que el país necesita soluciones audaces más que soluciones prudentes. Sin embargo, para Ellacuría era fundamental aprender a temperar la pasión por la justicia, para que esta no termine convirtiéndose en venganza. Semejante peligro solo se podría sortear mediante la práctica de otras dos virtudes a la vez: justicia y misericordia.

Difícil tarea la que imponía Ellacuría a los graduados universitarios de 1986. Quizá era demasiado pedirles, dadas las circunstancias históricas que les tocó vivir entonces, y porque era poco lo que cada uno de ellos podía realizar individualmente desde el ejercicio de sus profesiones. He ahí el desafío para nuestro tiempo, si lo modificamos y lo trasladamos hacia las universidades. Ello implicaría para las universidades asumir con gran responsabilidad el desafío de formar sistemáticamente los constructores y artesanos de la paz que necesita El Salvador hoy. 